\title{
Constitucionalizando a conectividade: a articulação constitucional da sociedade mundial
}

DOI: 10.15175/1984-2503-202012205

\author{
Poul F. Kjaer \\ Traduzido por Ana Carolina Paranhos de Campos Ribeiro**
}

\section{Resumo}

O Direito Global estrutura-se, predominantemente, por normas de conectividade, que se diferenciam das normas de coerência e de possibilidade. A centralidade das normas de conectividade emerge da própria função do direito global, que é a de aumentar a probabilidade de transferência de componentes sociais condensados, como capital econômico e produtos, doutrinas religiosas e conhecimento científico, de um contexto juridicamente estruturado para outro, no âmbito da sociedade mundial. Esse é o caso desde o colonialismo e o direito colonial até as atuais cadeias produtivas globais e os direitos humanos. Tanto o direito colonial quanto os direitos humanos podem ser entendidos como ferramentas à serviço da função de constitucionalização orientada à estabilização e à facilitação da conectividade. Por conseguinte, é possível compreender o colonialismo e a governança global contemporânea como equivalentes funcionais, mas não como equivalentes normativos.

Palavras-chaves: Direito global; normas de conectividade; direito colonial; direitos humanos.

\section{Constitucionalizando la conectividad: la articulación constitucional de la sociedad mundial}

\section{Resumen}

El derecho global se estructura, predominantemente, con normas de conectividad, que se diferencian de las normas de coherencia y de posibilidad. La centralidad de las normas de conectividad emerge de la propia función del derecho global, que es la de aumentar la probabilidad de «transferencia» de componentes sociales condensados, como capital económico y productos, doctrinas religiosas y conocimiento científico, de un contexto jurídicamente estructurado a otro, en

\footnotetext{
* Professor do Departamento de Administração, Política e Filosofia da Copenhagen Business School. Dinamarca. E-mail: pfk.mpp@cbs.dk. (1) https://orcid.org/0000-0002-8027-3601

Versões anteriores deste artigo foram apresentadas em duas conferências: "Constituições Societárias em Regimes Transnacionais", Cardiff University, 30/06 a 01/07/2017, e "A política da (des)conectividade", Chinese Academy of Sciences, Pequim, 30/11-01/12/2017. A pesquisa que embasou este artigo contou com o apoio do Conselho de Pesquisa Europeu, mediante recursos do fundo ITEPE-312331. Cf. Kjaer (2018a).

** Bacharel em Relações Internacionais, licenciada em História e Mestre em Direito pela Universidade de Brasília. E-mail: anacarolinaparanhoscr@gmail.com. (1) https://orcid.org/0000-0002-9303-006X
} 
el marco de la sociedad mundial. Ese es el caso desde el colonialismo y el derecho colonial hasta las actuales cadenas productivas globales y los derechos humanos. Tanto el derecho colonial como los derechos humanos pueden ser entendidos como herramientas al servicio de la función de "constitucionalización» orientada a la estabilización y la facilitación de la conectividad. Por consiguiente, es posible comprender el colonialismo y la gobernanza global contemporánea como equivalentes «funcionales», pero no como equivalentes normativos.

Palabras clave: Derecho internacional; normas de conectividad; derecho colonial; derechos humanos.

\title{
Constitutionalizing Connectivity: The Constitutional Grid of World Society
}

\begin{abstract}
Global law settings are characterized by a structural pre-eminence of connectivity norms, a type of norm which differs from coherency or possibility norms. The centrality of connectivity norms emerges from the function of global law, which is to increase the probability of transfers of condensed social components, such as economic capital and products, religious doctrines, and scientific knowledge, from one legally structured context to another within world society. This was the case from colonialism and colonial law to contemporary global supply chains and human rights. Both colonial law and human rights can be understood as serving a constitutionalizing function aimed at stabilizing and facilitating connectivity. This allows for an understanding of colonialism and contemporary global governance as functional, but not as normative, equivalents.
\end{abstract}

Keywords: Global law; connectivity norms; colonial law; human rights.

\section{La constitutionnalisation de la connectivité et l'articulation constitutionnelle de la société mondiale}

\section{Résumé}

Le droit international est principalement structuré autour de normes de connectivité, qui se différencient des normes de cohérence et de possibilité. La centralité des normes de connectivité émerge de la fonction même du droit international, qui consiste à augmenter la probabilité de transfert de composantes sociales condensées, telles que le capital économique et autres produits, doctrines religieuses et connaissances scientifiques, d'un contexte juridiquement structuré à un autre dans le cadre de la société mondiale. C'est le cas depuis le colonialisme et le droit colonial jusqu'aux chaines actuelles de production mondialisée, en passant par les droits de l'Homme. Aussi bien le droit colonial que les droits humains peuvent être entendus comme des outils au service d'une constitutionnalisation visant la stabilisation et la facilitation de la connectivité. Par conséquent, on peut comprendre le colonialisme et la gouvernance mondiale contemporaine comme des équivalents fonctionnels, mais pas comme des équivalents normatifs.

Mots-clés : Droit international ; normes de connectivité ; droit colonial ; droits de l'Homme. 


\section{将联通性宪法化：全球社会规范的确立}

\section{摘要}

全球法律主要由联通性规范构成，联通性规范与 “连续性规范” 和 “可能性规范” 不同。联通性规 范的核心是保证全球范围内，经济资本，产品，宗教教义和科学知识的畅通流转，并在法律背景下 规范全球的联通性。从殖民主义和殖民法到当前的全球生产链和人权法，人们所关注的都是联通 性。因此，殖民法和人权法都可以被理解为旨在稳定和促进世界联通性的工具。我们可以将殖民主 义和当代全球治理法解读为在功能上类似，但在规范上并不相同的两种历史过程。

关键词: 全球法; 联通标准; 殖民地法; 人权。

\section{Introdução}

O presente artigo propõe uma mudança epistemológica no contexto do debate sobre a metamorfose do constitucionalismo. Uma mudança que transita do foco na diferenciação para o foco na conectividade, isto é, um foco em processos "intersistêmicos" - não mais intrasistêmicos -, em sentido semelhante ao expresso na noção de interlegalidade originalmente cunhada por Boaventura de Sousa Santos (2002, p. 437) em um discurso na Cardiff University.

Abordagens sistêmicas sobre o constitucionalismo trazem, como consequência da arquitetura e das premissas básicas da teoria, um foco primário no interior dos mundos de sistemas e nas funções constitutivas e limitantes da lei em relação aos processos sociais de base, como a economia, a política, a ciência, os meios de comunicação, entre outros (LUHMANN, 1990; TEUBNER, 2012). Embora a perspectiva "internalista" seja tanto necessária quanto útil, ela retira a ênfase no aspecto da conectividade, ou seja, em como o fluxo de uma sustentada e contínua comunicação social é aumentado em uma escala global em um mundo caracterizado pela mútua contextualidade. Sem desconsiderar a questão crucial acerca da integridade interna das comunicações sistemicamente organizadas e o papel das normas jurídicas para obter essa integridade, pretende-se tratar da clássica questão sociológica sobre "como a sociedade é possível?" (SIMMEL, 1908) sob a condição estrutural da existência da sociedade mundial e o papel das normas e constituições nesta reflexão. O ponto de partida não seria o descarte da ciência sistêmica, mas o desenvolvimento de uma perspectiva ortogonal, uma perspectiva complementar às teorias sistêmicas clássicas, preenchendo assim 
um ponto cego a partir de uma estratégia de metamorfose teórica que se inicia desde o interior da teoria de sistemas e se conclui em outro lugar.

A noção de uma sociedade mundial, isto é, a proposição de que existiria apenas uma sociedade no nosso mundo, é central para a ciência sistêmica. Essa proposição faz referência à noção de Edmund Gustav Husserl sobre os "horizontes comuns de oportunidade", e, portanto, estimula uma conectividade potencial em escala global. Este artigo vai além da proposição geral de uma sociedade mundial como pensada por Niklas Luhmann ao trazer a compreensão de normas jurídicas globais como instrumentos de conectividade que cumprem um papel relevante para a constituição da sociedade mundial. Pautando-se na revisão de uma vasta literatura acerca da função das normas jurídicas, a perspectiva que será desenvolvida propõe que normas jurídicas não somente limitam a conectividade, mas também a viabilizam. Esse argumento é central para se compreender a posição e a função das normas jurídicas globais, uma vez que a sociedade mundial, paradoxalmente, consiste em "vários mundos". A sociedade mundial é uma sociedade sem um centro único, que apresenta não somente uma diferenciação horizontal entre os sistemas funcionais, mas também uma diferenciação vertical entre os processos decorrentes dos princípios organizadores nos âmbitos local, nacional e transnacional (SASSEN, 2006). Ademais, paradoxalmente, o adensamento da globalização resultou em um aumento - e não na redução - da diversidade. A lógica da diferenciação associada a uma sociedade mundial sem um centro precisa, então, ser complementada pela lógica da conectividade. Foi frente a este contexto que as normas jurídicas globais emergiram enquanto instrumentos de conectividade.

Além da clássica função das normas em relação a servirem para estabilizar expectativas, as normas jurídicas globais estão especificamente orientadas para a estruturação de "transferências", isto é, à extração, transmissão e implantação dos componentes sociais condensados (Sinnkomponente) de um contexto para outro. Isso se dá em relação a todos os sistemas funcionais, porquanto as transferências sejam observadas em relação às decisões políticas, decisões jurídicas, produtos e capital econômico, conhecimento científico, e assim por diante. A partir desta orientação em relação às transferências que as normas jurídicas globais adquirem o papel de instrumentos que facilitam a conectividade. ${ }^{1}$

\footnotetext{
${ }^{1}$ N.T. No original, connectivity-enhancing instruments.
} 
Isso também se reflete na transformação evolutiva das normas jurídicas destinadas a estabilizar processos globais em curso. Uma das mais significativas - talvez, a mais relevante das - transformações estruturais com a qual o direito contemporâneo e as ciências sociais estão se debatendo seria a contínua descentralização do mundo após a implosão do mundo Eurocêntrico e o gradual declínio da preponderância do Ocidente. Essa transformação ainda não foi completamente compreendida nem em termos empíricos nem conceituais, deixando o mundo em um vácuo de incerteza (BRUNKHORST, 2010). Observando especificamente a infraestrutura legal institucionalmente enraizada da sociedade mundial, essa transformação pode ser entendida como a passagem do colonialismo para a governança transnacional e os direitos humanos. Tanto o colonialismo quanto a governança transnacional contemporânea vão além da dimensão econômica, embora, simultaneamente, a estruturação das transferências econômicas permaneça central a ambos (XIFARAS, 2016).

A partir de um olhar minucioso para a dimensão econômica, é possível constatar um salto da dimensão econômica do colonialismo para as cadeias produtivas globais como a principal mudança na estruturação do processo global das transferências econômicas. Tanto o colonialismo quanto cadeias produtivas globais contam com instrumentos jurídicos e ambos se caracterizam por uma hierarquia normativa, que permite revelar sua constituição. No entanto, as normas substanciais sob as quais ambos se assentam são muito diferentes, permitindo que se argumente que a dimensão econômica do colonialismo e das cadeias produtivas globais são equivalentes funcionais, mas não equivalentes normativos. Em outras palavras, a transformação do colonialismo para as cadeias produtivas globais implica uma inflexão fundamental na rede constitucional da sociedade mundial.

Este artigo inicia-se com dois exercícios de contextualização denotativa, que delineiam brevemente o contorno da sociedade mundial e do direito global. Em seguida, prossegue-se ao estudo do estado-de-coisas das teorias atuais com vistas a localizar uma alternativa capaz de trilhar um caminho intermediário entre as perspectivas de unificação e as de pluralismo radical em relação ao direito global. Depois, busca-se consolidar essa proposta alternativa, primeiro, a partir do desenvolvimento da noção da conectividade das normas como um tipo particular de norma jurídica que, por razões estruturais, tende a ganhar proeminência em relação aos processos sociais globais em curso e, em segundo, mediante uma breve reconstrução dos principais estágios da transformação da dimensão econômica do colonialismo para as cadeias produtivas globais e os direitos humanos. $\mathrm{O}$ 
artigo termina apontando algumas reflexões sobre as implicações destes argumentos para a compreensão da constitucionalização da sociedade mundial.

\section{O contexto societário: o surgimento da sociedade mundial}

Ao introduzir o conceito de sociedade mundial no início dos anos 1970, Luhmann encapsulou uma gama de eventos que, décadas depois, entraria na narrativa mais aprofundada sobre a globalização. ${ }^{2}$ O elemento central do conceito de Luhmann (1971/2009) sobre a sociedade mundial baseia-se no conceito de Husserl sobre os horizontes de intencionalidade, ao qual Luhmann atribuiu nova faceta ao argumentar que, na sociedade mundial, o mundo social por inteiro compartilha um conjunto comum de experiências potenciais. Luhmann estipulou um processo caracterizado pela fusão de horizontes (Horizontverschmelzung) no sentido de Gadamer (1986/1990, p. 310). Tendo em vista que o conceito de "horizontes "está imerso no tempo - assim como se constitui no próprio tempo -, esse desdobramento está estreitamente relacionado à emergência de um tempo mundial, conforme se consolidou na segunda metade do século XIX, isto é, um conceito unitário de tempo que permite a comunicação ao redor do mundo sem que se perca tempo (LUHMANN, 1997, p.145 et seq.).

É possível identificar três fases na história do surgimento da sociedade mundial. A primeira teria sido a descoberta pela Europa do mundo como um globo singular, conhecimento cristalizado na aurora dos descobrimentos científicos e das grandes navegações dos séculos XV e XVI, momento em que também houve a construção de uma ordem jurídica eurocêntrica que reivindicou para si validade no mundo como um todo (KJAER, 2014; SCHMITT, 1950). A segunda é marcada pela sincronização do mundo, conforme se observa mediante a noção de um tempo mundial a partir de 1850, no marco das mudanças e inovações tecnológicas, a exemplo dos navios, das estradas de ferro, do telégrafo, juntamente com a segunda onda do imperialismo expansionista da Europa, seguido pelo imperialismo japonês e norte-americano, o que levou a processos conectados e simultaneamente em curso em termos globais (OSTERHAMMEL, 2014). Isso se expressa na globalização dos sistemas funcionais em relação à economia, ao direito, aos meios de comunicação (mass media), à política, à ciência, entre outros, por meio da semântica das novas articulações como: economia mundial, política internacional, literatura mundial

\footnotetext{
2 Sobre a Escola de Bielefeld quanto à sociedade mundial, conferir: Stichweh (2000). Sobre a Escola de
} Stanford, conferir: Meyer (1997). 
(STICHWEH, 2008). A terceira fase se define a partir dos anos 1960, com a intensificação destes processos, como previsto por Luhmann, por meio do contínuo aumento dos fluxos de comunicação global frente às novas tecnologias, a exemplo do transporte de containers, comunicação via satélite, internet, bem como das profundas mudanças nos marcos legais e regulatórios, o que facilitou a liberalização dos fluxos financeiros nas últimas décadas do século $X X$ e, por conseguinte, repercutiu em um extraordinário aumento das trocas e interações sociais em escala global.

No entanto, embora o diagnóstico destes eventos seja claro, o conceito de sociedade mundial continua indeterminado (AMSTUTZ; KARAVAS, 2009). As teorias de sistemas postulam a predominância da diferenciação funcional por meio da sociedade mundial. De fato, existem efetivamente sistemas globais de economia, comunicação em massa, política, o que sugere que outras formas de diferenciação, por exemplo, centro/periferia, estratificação e diferenciação em segmentos, têm sido internalizadas. Isso demonstra que outras formas secundárias de diferenciação ocorrem dentro dos próprios sistemas funcionais estabelecidos. Essa realidade se reflete, por exemplo, na estratificação dos rankings globais na área da educação superior ou na confiança dos diagnósticos das bolsas de Londres e Nova York quanto aos indicadores econômicos do centro e da periferia.

Questiona-se, porém, o grau e a profundidade do desenvolvimento destes processos. Continuam limitadas as partes do mundo em que a modernidade, definida como a prevalência da diferenciação funcional (LUHMANN, 1997, p. 145), ganhou domínio protuberante, notadamente a área do Atlântico Norte. Aliás, há muitas cidades globais caracterizadas por apresentar fortes traços de modernidade (SASSEN, 2001), mas, na maior parte do mundo, a diferenciação funcional continua a interagir de modo ortogonal em relação às demais formas de diferenciação - centro-periferia, segmentação e estratificação - de modo a tornar empiricamente questionável a hipótese de uma disseminada predominância da diferenciação funcional (NEVES, 1992). Isso poderia ser apenas uma mera questão de "Causalidade no Sul" (LUHMANN, 1995), mas a evolução social é cega e inexistem garantias para uma futura duplicação para o resto do mundo da modernização que se desdobrou pela Europa e América do Norte. Somente uma condição permanece observável, caracterizada pela miscigenação comunicativa e pela crioulização, ${ }^{3}$ isto é, a mistura de diferentes tipos de comunicação, a ponto de não ser mais possível defender uma pureza inerente aos sistemas funcionais (AMSTUTZ, 2009; KJAER, 2012). Por

\footnotetext{
${ }^{3}$ N.T.: No original, communicative crossbreeding and creolization.
} 
conseguinte, embora os sistemas funcionais tenham um alcance mundial, eles operam, na maioria dos contextos, com um limitado grau de destilação e somente como uma fina camada de verniz que aparece sob formas mais enraizadas de comunicação (KJAER, 2012). É o caso de contextos pós-coloniais, nos quais surgiram interstícios entre as operações dos sistemas formais impostos pela potência estrangeira e as formas de comunicação local pré-existentes (AMSTUTZ, 2009; MBEMBE, 2006).

\section{O contexto jurídico: o surgimento do direito global}

O gradual surgimento e a intensificação das trocas sociais no marco da sociedade mundial estiveram acompanhados por e, em grande medida, também se desenvolveram pela convergente edificação do direito global enquanto um campo jurídico emergente. Emergente porque ainda "incompleto", o que torna o direito global um fenômeno jurídico, mas não um (sub)sistema legal plenamente consolidado (LE GOLF, 2007). Isso se explica porque a própria delimitação do fenômeno do direito global em relação ao direito interno (doméstico), internacional, transnacional e comunitário continua turva, imprecisa. O direito interno, em uma perspectiva positivista clássica, pode ser compreendido como as leis de estados nacionais formados a partir do conceito de soberania. Partindo de um um paralelismo em relação ao direito interno, o direito internacional clássico seria tipicamente compreendido como as leis entre estados, o que viabiliza a exclusão de outros tipos de leis e de figuras normativas que não caberiam em um paradigma conceitual interestatal (KLABBERS, 2013). Já o direito transnacional seria compreendido como a categoria em que qualquer lei que, de algum modo, em termos de jurisdição, origem ou efeito, ultrapassa as fronteiras nacionais. Por conseguinte, o direito transnacional, em seu sentido original, se refere principalmente, embora não de forma exclusiva, aos efeitos externos do direito interno (AVBELJ, 2016; JESSUP, 1956; WALKER, 2015).

A recente noção de direito global surgiu justamente neste contexto. De acordo com Neil Walker, o direito global poderia ser descrito como o mero uso retórico da palavra "global", por exemplo, por empresas e pessoas jurídicas que se apresentam como atores globais. Pode referir-se a um tipo específico de normas com (ou quase com) uma escala global, principalmente no âmbito das instituições que atuam no nível mundial, como a Organização das Nações Unidas (ONU) ou a Organização Mundial do Comércio (OMC). No entanto, em contraste com essas perspectivas, Walker conceitua o direito global como qualquer tipo de norma, independentemente de sua origem ou orientação, que, em princípio, pode ou poderia 
ser ilimitada em termos de alcance. Dessa forma, o direito global invocaria uma validade não restrita a um específico povo ou território, embora, devido a questões práticas e concretas, ele possa ser limitado em algumas circunstâncias (AVBELJ, 2016). A título de ilustração, Walker (2015) considera que o direito que rege a União Europeia representaria a essência do direito global, uma vez que opera de forma não estritamente relacionada a limites territoriais e que, a princípio, não é limitada em seu alcance. ${ }^{4}$

Porquanto a dimensão universal seja uma característica marcante do direito global, duas outras dimensões favorecem uma compreensão substancial deste fenômeno, que seriam a de "conectividade" 5 e de transferência. A estrutura básica da sociedade mundial consiste em sistemas funcionais globais, embora enfrentando uma relevante indeterminação na maior parte do mundo quanto à relação entre as várias lógicas de diferenciação e a crescente fragmentação interna dos sistemas funcionais, o que implica que os sistemas funcionais reconfiguram essa indeterminação de diversos modos. Especificamente, essa reconfiguração ocorre em uma realidade em três camadas, e não apenas quando se trata dos sistemas globais de política e direito. Se, por um lado, o sistema teórico de N. Luhmann enfatiza somente a fundação horizontal dos sistemas funcionais, que, a priori, gozam de status semelhante, por outro lado, não se pode compreender a sociedade mundial sem sua fundação vertical que abarca os processos locais, nacionais e internacionais (HALLIDAY; SHAFFER, 2015, SASSEN, 2006). Esta complexa matriz viabiliza uma gama de observações, transferências e colisões entre as unidades situadas quer na mesma camada, quer em outras camadas. Dessa forma, é possível conceituar o direito global como a aplicação universal do fenômeno jurídico da chamada "conectividade"6 (AMSTUTZ; KARAVAS, 2009; SANTOS, 2002), cuja natureza é a de materialmente facilitar a separação, transmissão e incorporação dos componentes sociais de um contexto jurídico para outro. Assim, o direito global pode ser definido como um arcabouço jurídico edificado a partir da descentralização e que se manifesta na interlegalidade (PALOMBELLA, 2012). É universal na medida em que aparece em um número amplo de contextos ao redor do mundo ao mesmo tempo em que produz efeitos autônomos nos diferentes locais: o direito global não é uma mera reprodução de acoplamentos estruturais ou de caixas pretas que servem apenas como meios de transmissão entre diferentes (sub)sistemas. Pelo contrário, a separação, transmissão e incorporação de componentes sociais condensados de um

\footnotetext{
4 Para a crítica de "um direito sem fronteiras" ("boundaryless law") conferir: Supiot (2009).

${ }^{5}$ N.T.: No original, in-between-ness.

${ }^{6}$ N.T.: No original, in-between.
} 
(sub)sistema para outro mediante o direito global implica que os próprios componentes sociais e seu significado são modificados no curso destes três processos. Em outras palavras, o que é retirado de um contexto normativo não é igual ao que será incorporado.

\section{A proposta: abrindo a terceira via entre unificação e pluralismo}

Uma implicação lógica da presente argumentação seria que teorias sistêmicas devam ser complementadas com os elementos da teoria da "conectividade", 7 pois edificam uma relação ortogonal entre elas. Tal desdobramento vai além do escopo deste artigo, mas pode oferecer insights adicionais sobre o direcionamento do direito global. ${ }^{8}$

Como síntese, o direito global é constituído por e combina elementos do direito local, nacional, internacional e transnacional, a despeito de também (re)produzir normas e princípios jurídicos próprios. O direito internacional público, definido como as regras e normas guiando as relações entre governos e outras entidades estatais, assim como o direito internacional privado, definido como um conjunto de regras para se selecionar as leis aplicáveis em cada tipo de contrato em constelações transfronteiriças, incluindo a competência das Cortes em casos de disputas (LE GOLF, 2007), servem como veículos ou instrumentos deste direito global. O mesmo ocorre com a disciplina acadêmica do direito comparado, pois tem, como elemento central, a comparação entre diferentes sistemas jurídicos, o que viabiliza a análise das divergências sob as quais se fundamentam o direito internacional público e privado e, assim, possibilita a harmonização de esforços para propósitos convergentes. Dessa forma, o direito comparado, enquanto disciplina acadêmica, teria o condão de gerar efeitos performáticos que são essenciais para o direito global. O direito internacional econômico, definido como regras e normas organizando as transações econômicas além das fronteiras nacionais, incluindo o subcampo do direito comercial e financeiro, bem como o controverso fenômeno da Lex Mercatoria, isto é, os princípios vetores dos contratos comerciais transnacionais, são também peças essenciais do direito global. Simultaneamente, a própria noção de direito global torna-se mais ampla quando, em vez de se restringir, vai além das transações econômicas e estipula um impacto contextual abrangente no conjunto da "sociedade como tal" (LE GOLF, 2007).

Com a ênfase na universalidade descentralizada do direito global, um caminho é aberto entre as principais posições até o momento utilizadas para abordar o tema:

\footnotetext{
7 N.T.: No original, theory of the in-between.

${ }^{8}$ Conferir: Kjaer (2006).
} 
unificação e pluralismo ou as perspectivas de convergência e divergência. A corrente da unificação tem sido mais claramente desenvolvida a partir do direito internacional público, sendo a posição que defende a existência de uma singular hierarquia de normas na sociedade mundial, tradicionalmente associando essas normas básicas à Carta das Nações Unidas (UNITED NATIONS, 1945), entendida como a "constituição do mundo" à luz da ideia de uma normatividade unificada (FASSBENDER, 2008). Uma variação teórica menos robusta desta corrente defende a existência de um único sistema jurídico constitutivo para o mundo, atribuindo ao direito internacional público o status de um sistema jurídico fundacional, de meta sistema constitutivo da sociedade (conferir: THORNHILL, 2016). Também no direito internacional privado os esforços de harmonização têm sido prioritários, como se pode observar na tentativa de se estabelecer um Código Civil Europeu (conferir: BAR et al., 2009) e a proposta de se criar um Código Comercial Global (LANDO, 2004). Em contraposição, a corrente pluralista ressalta a natureza descentralizada e não hierárquica do direito na sociedade mundial, enfatizando tanto as perspectivas de direito concorrente, isto é, do choque entre leis diferentes em um mundo fragmentado (FISCHER-LESCANO; TEUBNER, 2006; JOERGES; KJAER; RALLI, 2011; KOSKENNIEMI, 2009), quanto à dimensão política da diversidade jurídico- normativa (KRISCH, 2010).

Essa paradoxal unidade na diversidade pode, contudo, ser dissolvida por meio de uma análise temporal que revele o desdobramento histórico do direito global e das normas jurídicas globais, isto é, por meio de uma sociologia histórica do direito global voltada ao estudo da inflexão que levou à criação das normas jurídicas globais e que seja complementada por uma perspectiva teórica evolucionista capaz de acompanhar a transformação das normas jurídicas globais ao longo do tempo e seus efeitos internos e externos. ${ }^{9}$

A partir desta perspectiva, um possível insight seria o de que as normas jurídicas globais, em uma forma imperial, isto é, transcendente e universal, teriam precedido o direito westfaliano dos estados nacionais. ${ }^{10}$ Ademais, é possível constatar que o direito moderno dos estados nacionais e o arcabouço jurídico moderno da governança transnacional surgiram de forma concomitante ao longo de séculos de processos dialéticos e de reforço mútuo (KJAER, 2014, p. 31). Primeiro, a gradual emergência dos estados territoriais na

\footnotetext{
${ }^{9}$ Sobre a sociologia histórica do direito, conferir: Madsen e Thornhill (2014). Para reflexões sobre o método específico da pesquisa constitucional, ver: Thornhill (2016, p. 12).

10 Quanto a esta perspectiva, conferir: Brunkhorst (2014). Neil Walker $(2015$, p. 86) também identifica um conjunto de abordagens histórico-discursivas em relação ao direito global, mas reconhece como recente o debate contemporâneo sobre o constitucionalismo global, a constitucionalização do direito internacional e o direito global administrativo, descartando uma perspectiva histórica de longo prazo sobre o direito global.
} 
Europa ocidental a partir do século XVI e a simultânea edificação de impérios coloniais de escala global regidos pelo direito colonial. Em segundo, houve a globalização do modelo dos estados soberanos a partir de uma transformação estrutural provocada pela queda dos impérios europeus às vésperas da Primeira Guerra Mundial e, posteriormente, reforçada pela descolonização em meados do século $\mathrm{XX}$, acompanhada simultaneamente pela substituição do direito colonial pelo arcabouço da governança global e do direito contemporâneo (KJAER, 2014, p. 17).

\section{O problema: finalidade e performance das normas globais}

A estrutura da sociedade mundial e do direito global como descrita nas seções anteriores permite um novo olhar para a clássica pergunta sociológica: "como a sociedade é possível?" (SIMMEL, 1908). A progressiva descentralização do mundo eurocêntrico e, no tempo presente, do mundo Ocidental, revela, paradoxalmente, que a crescente globalização tem ampliado, e não reduzido, o viés descentralizado da sociedade mundial (KJAER, 2018b). Assim, a conectividade em uma sociedade mundial descentralizada se torna um dos principais temas contemporâneos - e, talvez, o mais crucial, pois esse processo registra a transição de uma relativa predominância de lógicas de diferenciação para lógicas de conectividade, isto é, de conectividade intersistêmica (KJAER, 2006, p. 77). Como os sistemas tendem a aumentar a conectividade em relação aos processos globais em curso, marcados por uma indeterminação quanto a qual forma de diferenciação seria a mais importante em várias partes do mundo, e, especialmente, em situações que exigem a conectividade entre componentes de comunicação localizados em diferentes contextos caracterizados por diferentes constelações e formas de diferenciação? $E$ como a fragmentação interna dos sistemas funcionais afeta esses processos globais?

Como reflexo deste estado de coisas, surgiram novos tipos de intermediários, em geral, baseados em redes e consolidados por meio de instrumentos jurídicos (KJAER, 2010). As cadeias produtivas globais, o regime internacional de direitos humanos e o regime de mudança climática são exemplos dessas estruturas intermediárias. Estrategicamente, tendem a se localizar em um sistema funcional específico, como o econômico, o jurídico ou o - imaginário, mas socialmente real - sistema de meio ambiente, assim como partilham uma dupla razão de ser: internamente, a de dar coerência interna e viabilizar a conectividade no âmbito de seus sistemas funcionais em uma escala global e, externamente, (re)contextualizar componentes comunicativos quando eles são transferidos de um contexto a outro. Por 
exemplo, a função externa ocorre quando existe a prevalência de uma lógica de diferenciação em um contexto e que, na transferência para outro contexto, enfrenta uma realidade não marcada pela mesma lógica. Logo, sua dupla função é a de engendrar uma paradoxal unidade em meio a sistemas funcionais e múltiplos contextos sociais, facilitando a transferência de componentes sociais condensados entre os diferentes contextos.

Na sociedade mundial, o principal elemento da conectividade é a transferência. De acordo com Rudolf Stichweh (2006), a transferência de componentes sociais condensados (Sinnkomponente) - conceito este bastante usado pela literatura sobre transferências jurídicas - teria ao menos cinco características. Primeiro, os objetos da transferência são compactos e unidades carregadas de sentido, como as decisões políticas e administrativas, as sentenças judiciais e opiniões jurídicas, os produtos econômicos, o capital financeiro, o conhecimento científico e tecnológico, todos esses formando uma realidade claramente demarcada e possuindo uma orientação funcional identificável. Segundo, um ato de transferência implica constatar que as unidades transferidas possuem um valor informativo intrínseco e que, provavelmente, elas serão reconhecidas e capazes de produzir efeitos no contexto que as recepciona. Terceiro, a transferência envolve o cruzar de fronteiras nacionais, uma vez que as unidades são levadas de um contexto para outro, sendo levadas para além da fronteira de seu contexto, o "emissor", e adentrando em outro contexto, o "receptor". Quarto, a transferência abarca uma questão de distância, seja espacial ou temporal. Quinto, certa permanência é necessária, a fim de consolidar o fundamento para a repetição dos processos de transferência dos componentes sociais condensados que sejam similares ou relacionados entre o contexto de emissão e o de recepção ao longo do tempo (STICHWEH, 2006). ${ }^{11}$

Em acréscimo à lista de Stichweh, cabe argumentar que normas de transferência e conectividade são essenciais para aumentar a possibilidade de transferências bem sucedidas. Quando introduziu o conceito de sociedade mundial, Luhmann cunhou a hipótese especulativa segundo a qual o advento da sociedade mundial implicaria uma relativa redução da centralidade de expectativas normativas e de aumento das expectativas cognitivas para a reprodução da própria sociedade mundial. Ou seja, fenômenos sociais e processos que dependem mais fortemente de expectativas normativas, como o direito, a política e a moral, iriam se enfraquecer, de acordo com a previsão de Luhmann, enquanto fenômenos que dependem mais profundamente em expectativas cognitivas, como a

\footnotetext{
${ }^{11}$ Para uma visão mais detalhada sobre as transferências, ver: Kjaer (2018b).
} 
economia, a tecnologia e a ciência, iriam se fortalecer e ganhar maior relevância global LUHMANN, 1971/2009). As expectativas normativas são compreendidas como as expectativas almejadas, mesmo que ainda não realizadas ou cumpridas, tornando-se, portanto, expectativas contrafactuais, isto é, contrárias às estabilizadas na realidade. Por outro lado, as expectativas cognitivas são entendidas como as que são modificadas no processo de não realização ou de não comprovação (LUHMANN, 1972/2008, p. 40). Vinte anos antes da publicação da obra "Direito e Democracia: entre facticidade e validade", ${ }^{12}$ de Jürgen Habermas, baseada na distinção entre a esfera fática e a normativa, como se deduz do título, Luhmann explicitamente rejeitou essa distinção e a substituiu pela distinção entre expectativas "normativas" e expectativas "cognitivas". Uma das vantagens da proposta pioneira de Luhmann é a de que as expectativas normativas são tão reais quanto as expectativas cognitivas. O mundo social é caracterizado por uma dupla realidade (Realitatsverdopplung) entre o mundo que faticamente existe e uma igualmente real articulação comunicativa contrafactual de como o mundo deveria ser (LUHMANN, 1996).

Mesmo que se aceite a argumentação sobre a equivalente realidade das articulações normativas e cognitivas, ainda é possível questionar empiricamente a validade da primeira, uma vez que a sociedade mundial tem observado a normatividade, expressa por meio de expectativas, sair do centro da agenda. Os processos globais em curso não recorrem menos às normas do que os processos locais e nacionais. ${ }^{13}$ Pelo contrário, são orientados e recorrem a um subtipo específico de normas associadas aos processos locais e nacionais.

À luz da filosofia analítica, o foco das normas recai em sua validade, isto é, se uma dada norma é a apropriada ou não. ${ }^{14}$ No entanto, sob o prisma sociológico, a validade não é o mais importante. Desta perspectiva emergem duas realidades contrastantes que são particularmente relevantes para os processos globais em curso, que seriam as normas de coerência e as normas de possibilidade, às quais se acrescenta ainda mais uma alternativa, a de normas de conectividade.

As "normas de coerência" partem do entendimento tradicional da sociologia, segundo o qual as normas tendem a ser instrumentos de coletividade, cuja finalidade é dar coerência a um grupo, seja uma tribo ou não, por meio da prescrição de ações consideradas desejáveis para os membros do grupo e de injunções e sanções voltadas à encorajar o cumprimento das normas (BLAKE; DAVIS, 1964; HYDÉN, 2002, p. 96; PARSONS, 1937/1968).

\footnotetext{
${ }^{12}$ N. T.: No original, Faktizität und Geltung, publicado em Frankfurt am Main, em 1992.

13 Sobre o tema, consultar: Kjaer (2014).

14 Consultar, por exemplo: Korsgaard, (1996).
} 
As "normas de possibilidade" ou "programáticas" no âmbito da sociologia introduzem uma distinção e apontam a distância entre a realidade social fática percebida em um contexto social e perspectiva contrafactual. Em oposição às normas de coerência, as normas de possibilidade são instrumentos que permitem o desenrolar de alternativas em uma dada realidade social permitindo que sejam construídos caminhos futuros, de modo a acentuar a abertura (LUHMANN, 1974; MÖLLERS, 2015).

As "normas de conectividade" são uma terceira variação particularmente adequada ao contexto global. Elas contrastam com as duas primeiras, no sentido em que, embora compartilhem alguns elementos de cada uma, vão além de seu escopo. As normas de conexão, portanto, são consideradas instrumentos voltados a facilitar a separação, transmissão e incorporação de componentes sociais de um contexto para outro. Ou seja, orientam-se à separação de componentes sociais de um contexto e oferecem os princípios vetores para que sejam transmitidos e incorporados em outro contexto. Ademais, as normas de conectividade recorrem a sanções e a mecanismos de indução de aprendizagem práticoreflexiva em relação aos agentes dos diferentes contextos, melhorando as chances de transferências bem-sucedidas no futuro.

As normas de conectividade têm por objetivo abrir caminhos para as transferências e, simultaneamente, assegurar a compatibilidade entre processos em curso em diferentes contextos, mas uma forma de compatibilidade que assegure a estabilização do processo de transferência, em vez de gerar novas possibilidades, pois a compatibilidade não tem por intenção gerar coerência numa coletividade. Contudo, simultaneamente, o conceito de coletividade permanece relevante, uma vez que o aumento da chance de transferências bem-sucedidas exige o desenvolvimento de imagens internas ou de um imaginário coletivo tanto no contexto de emissão quanto no contexto receptor, o que tipicamente se manifesta nas construções jurídicas de uma coletividade, por exemplo, por meio dos conceitos jurídicos de "nação" ou de "comunidade", que servem para endereçar as transferências.

Essas três dimensões normativas também podem ser vistas como as representações das três esferas de significado de qualquer processo social: substancial, temporal e social (LUHMANN, 1984, p. 112). Isso corrobora o fato de que as três dimensões estão sempre presente em um dado tipo de norma, mas em proporções que variam de acordo com os diferentes tipos de processo social a que se destinam e das diferentes circunstâncias que regulam. Na prática, as três dimensões de normas engendram três tipos de intencionalidade expressos pelo objeto aos quais as normas se orientam, isto é, às coletividades, à articulação de futuros e aos atos de transferência, respectivamente, 
enquanto cada uma das três se fundamenta em três diferentes tipos de instrumento em sua intenção de interligar o fático e o contrafactual: punição, programas de articulação de futuros possíveis ou processos de perpetuação da conectividade.

Tabela 1. As três dimensões normativas

\begin{tabular}{|l|l|l|l|}
\hline $\begin{array}{l}\text { Dimensão } \\
\text { normativa }\end{array}$ & Coerência & Possibilidade & Conectividade \\
\hline $\begin{array}{l}\text { Tipos de } \\
\text { significado }\end{array}$ & Substancial & Tempo & Social \\
\hline $\begin{array}{l}\text { Objetos de } \\
\text { intencionalidade }\end{array}$ & Coletividades & Futuros articulados & Atos de transferência \\
\hline $\begin{array}{l}\text { Instrumentos de } \\
\text { concretização }\end{array}$ & Punição & & \\
\hline
\end{tabular}

Nesse sentido, frente à argumentação desenvolvida, seria possível compreender as normas jurídicas globais como normas fortemente inclinadas à dimensão conectividade, a ponto de se defender que a função ou finalidade última das normas jurídicas globais seria aumentar a probabilidade de conectividade. Isso se verifica, por exemplo, na constituição microeconômica da União Europeia, a constituição do mercado interno (TUORI, K. H.; TUORI, K., 2014, p. 13). Este mercado interno europeu pode ser um caso paradigmático de constituição jurídica de um processo social substancial, nomeadamente, as trocas econômicas, que estão voltadas à crescente conectividade econômica entre diversos e interligados contextos jurídicos por meio da introdução da hierarquia de normas conforme expresso nas quatro liberdades: de bens, serviços, capital e trabalho. Uma construção que não se depara com limitação territorial, conforme se comprova com a inclusão da Área Econômica Europeia (Groenlândia, Liechtenstein e Noruega) e com a inclusão parcial de outras ordens jurisdicionais ao mercado europeu. 


\section{Do colonialismo às cadeias produtivas globais}

O mercado interno europeu já estava estabelecido desde o Tratado de Roma de 1957 e sua criação esteve intrinsecamente relacionada à implosão dos impérios continentais e ultramarinos dos países Europeus e à progressiva descentralização do mundo eurocêntrico que se seguiu à queda dos Impérios (BRUNKHORST, 2014; FOSSUM; MENÉNDEZ, 2011). Não por acaso o chamado direito comunitário europeu (European Union Law) tem sido considerado o protótipo do direito global contemporâneo (WALKER, 2015, p. 110). Certamente, a despeito da vanguarda frente ao direito comunitário europeu, as normas do mercado interno representam apenas uma espécie de direito global, pois normas de conectividade de natureza jurídica podem ser identificadas na sociedade mundial. Regimes de meio ambiente - em relação à mudança climática -, de migração, de saúde pública global - em relação a epidemias -, de infraestrutura de turismo internacional, bem como outras redes de infraestrutura - de internet, aviação, telecomunicações, de logística portuária (LARKIN, 2013) - estão atrelados a normas de conectividade e ao direito global.

Outros dois exemplos seriam as cadeias produtivas globais e o regime global de direitos humanos. As cadeias produtivas globais estão predominantemente relacionadas ao direito internacional privado, enquanto o regime global de direitos humanos está predominantemente relacionado ao direito internacional público. Não obstante, a especificidade dos direitos humanos em termos de direito global se assenta não tanto em sua origem junto ao direito internacional público, mas sim à sua capacidade de constituir o direito global de forma autorreflexiva.

As cadeias produtivas globais tornaram-se o pilar da infraestrutura da economia mundial. Uma definição corrente as define como um sistema de organizações, pessoas, atividades, informação e recursos envolvidos na dinâmica de entrega de um produto ou serviço ao consumidor. ${ }^{15}$ Uma cadeia produtiva global implica ainda o espaço transfronteiriço, de modo que, o referido conceito pode ser atualizado da seguinte maneira: as cadeias produtivas globais seriam uma rede que abarca desde os fornecedores até os consumidores e que se engaja na extração, transmissão e incorporação de componentes sociais condensados, tal como, capital, produtos e pessoas, de um contexto societário para outros, que implica o cruzamento de fronteiras, bem como a reprodução de condições societárias que viabilizam os processos econômicos.

${ }^{15}$ Conferir: (SUPPLY..., 2003). 
Cabe distinguir as cadeias produtivas globais de sua gestão ou administração, que podem ser definidas como dinâmicas secundárias de estabilização das cadeias produtivas globais - para sua continuidade - baseadas em instrumentos organizacionais, administrativos e jurídicos com o objetivo de aumentar a possibilidade de extração, transmissão e incorporação de componentes sociais condensados com valor econômico de um contexto a outro. Nesse sentido, o conceito de "estabilização dinâmica" é relevante, pois implica que a camada de estabilização secundária seja dinâmica, em oposição a uma estrutura estática, mas com um ritmo de mudança que não prejudique os processos primários aos quais se orientam. Distinção entre cadeias produtivas e gestão de cadeias produtivas é, portanto, uma distinção entre estruturas cognitivas e normativas de expectativas, uma vez que as expectativas cognitivas estão constantemente em mudança, enquanto as expectativas normativas se caracterizam por um maior nível de estabilidade. Em contraste à visão de Luhmann sobre a constância, isto è, à imutabilidade das expectativas normativas, defende-se que as expectativas normativas mudam ao longo do tempo, mas em um ritmo menos acelerado que as expectativas cognitivas. Nas condições do mundo contemporâneo, as constituições podem ser compreendidas como instrumentos orientados a criar pontes entre o espaço temporal de primeira ordem, referente às expectativas cognitivas, e de segunda ordem, referente às expectativas normativas (KJAER, 2014, p. 45; 66).

As cadeias produtivas globais são tipicamente caracterizadas como um fenômeno do pós-guerra cuja relevância aumentou principalmente desde os anos 1980, frente a uma fundamental inflexão marcada por maior formalização e pelo aparecimento de formações autorreflexivas mediante a prática educacional, jurídica e organizacional que lida especificamente com as cadeias produtivas globais. Desse modo, a "invenção" das cadeias globais no pós-guerra teria sido, mais acertadamente, uma "reinvenção", tendo em vista que as cadeias produtivas globais têm sido um elemento constitutivo do comércio contemporâneo, mas também vigoram desde, pelo menos, o período do colonialismo europeu iniciado no final do século XV. Concretamente, o comércio de escravos trazidos da África exigiu uma complexa cadeia produtiva para o mundo árabe e para as Américas (MANNING, 1992). Por conseguinte, a dimensão organizacional do colonialismo pode ser considerada uma forma particular de gestão de cadeias produtivas, uma vez que o propósito do pacto colonial era a extração, transmissão e incorporação de componentes sociais condensados com, embora não exclusivamente, valor econômico. 
A principal transformação relativa ao surgimento das formas contemporâneas das cadeias produtivas globais é identificada na transição estrutural de uma organização colonial centro-periferia para regimes setoriais funcionalmente diferenciados no contexto do sistema econômico mundial. Nesse cenário, surgiram arcabouços normativos de segunda ordem firmemente entrelaçados que serviram como vetores para as cadeias produtivas globais. Um desdobramento imprescindível teria sido a proposição da "abordagem principiológica para se fazer negócios" inserida entre os dez princípios do Pacto Global da ONU, que abarca uma vasta área, incluindo direitos humanos, direito do trabalho, meio ambiente e combate à corrupção (UNITED NATIONS, 2020). Arcabouços normativos de natureza similar foram erigidas pelo UNCTAD e pela OCDE, assim como por organizações não governamentais ou, se não, ao menos por empresas multinacionais engajadas nas cadeias produtivas globais, desenvolvidos com o fito de regularizar e manter seu funcionamento. ${ }^{16}$

O equivalente funcional de Luhmann, que não deve ser equiparado com o funcionalismo clássico à la Durkheim, Malinowski, Merton ou Parsons, aporta três consequências: (i) um dado problema pode ser abordado de múltiplas formas; (ii) o problema primordial referente aos sistemas sociais está atrelado à próxima operação futura, (iii) os sistemas funcionais procuram expandir, universalizar seu escopo. ${ }^{17}$

Quando se consideram as estruturas de interligação voltadas ao desafio de estabelecer um arcabouço reprodutivo para extrair, transmitir e incorporar, o colonialismo e as cadeias produtivas globais podem ser considerados estruturas funcionais equivalentes, pois ambos procuravam resolver o mesmo problema. A forma contemporânea das cadeias produtivas globais se consolidou às vésperas da descolonização do século XIX, servindo como "substitutos" para o tipo de extração, transmissão e incorporação que ocorria no contexto do colonialismo. Essa imagem é reforçada por meio do relacionamento assimétrico dos fluxos ascendentes ${ }^{18}$ e decrescentes ${ }^{19}$ nos dois contextos. Os fluxos ascendentes seriam aqueles que seguem em direção ao receptor, isto é, ao consumidor, dos componentes sociais condensados no processo, enquanto os fluxos decrescentes seriam o movimento oposto.

\footnotetext{
${ }^{16}$ Conferir, por exemplo: Backer (2007).

17 Para uma explicação pedagógica sobre o conceito de equivalência funcional, consultar: Hanna (2017, p. 352). De forma mais genérica, consultar: Luhman (1968/1973) e Stichweh (2000).

18 N.T.: No original, upstream flow.

19 N.T.: No original, downstream flows.
} 


\section{Do colonialismo aos direitos humanos: constitucionalizando a conectividade}

Existe uma variação considerável de fundamentações jurídicas do direito colonial, como, por exemplo, a vertente belga, inglesa, dinamarquesa, holandesa, francesa, alemã, espanhola e portuguesa, o que abre um vasto espaço de pesquisa sobre direito colonial comparado que ainda precisa ser explorado (GRANDMAISON, 2005; KOSKENNIEMI, 2016). No entanto, essas vertentes do colonialismo partilham uma característica comum, que seria a sua estabilização mediante os princípios de dominium (propriedade), ius gentium (direito das gentes) e bellum iustum (guerra justa) (KOSKENNIEMI, 2011). Em sua dimensão econômica, o elemento central do colonialismo foi o desenvolvimento de uma rede horizontal de dominium baseada em contratos e em direitos de propriedade aplicáveis e cujo cumprimento era validamente exigível globalmente, juntamente com um princípio igualmente universal de livre comércio e de acesso a recursos. A essa orientação econômica se acoplou um princípio referente ao livre acesso às atividades missionárias cristãs nos territórios dominados. Em vez de anexar territórios, as trocas econômicas do capitalismo global e a transmissão de valores religiosos tornaram-se a fundamentação jurídica do colonialismo, engendrando um "direito à extração, transmissão e incorporação" regulado por normas de conectividade, o pilar principiológico sob o qual se assentavam as trocas globais (KOSKENNIEMI, 2011, p. 32). Contudo, devido à distinção entre cristãos e não cristãos sob a qual se firmou as normas de conectividade, elas abriram e reforçaram um espaço para trocas fundamentalmente assimétricas.

Desde a primeira fase do colonialismo, historicamente localizada entre os anos finais do século XV e a nacionalização da Companhia das Índias Orientais holandesa, em 1800; a conquista da Argélia pela França, em 1830; e a nacionalização da Companhia das Índias Orientais britânica, em 1858, os princípios do direito comercial privado providenciaram a sustentação normativa do colonialismo. Isso só se alterou, gradualmente, diante das contínuas transformações do colonialismo em empreendimentos diretamente conduzidos pelos Estados, o que provocou uma mudança de posicionamento que ditava a conquista e o domínio territorial. Essa inflexão, por exemplo, impactou e nutriu uma série de guerras entre 1821 e 1895 pelas quais a Companhia das Índias Orientais holandesa passou de uma coleção de postos comerciais ao redor do mundo a um epicentro de comando voltado ao exercício disseminado de controle territorial, assim como se manifestou na consolidação do império britânico na Índia por meios diretos e indiretos no século XIX, ou mesmo na colonização dos territórios não costeiros do continente africano a partir de 1870 . Esta 
inflexão deu forte impulso para o desenvolvimento do direito internacional contemporâneo, gestando vários arcabouços normativos de sustentação da conectividade global, vigentes de forma paralela e complementar aos anteriores princípios desenvolvidos do colonialismo privado. Esta inflexão implicou em crescente ênfase na responsabilidade "civilizadora" do colonialismo, que foi muito além do antigo direito ou dever de evangelização, e que enfatizou as noções de "processo social" e de "modernidade" ou "modernização". ${ }^{20}$

Somente com a terceira fase da globalização, iniciada no pós-guerra, a combinação entre as cadeias produtivas globais e o moderno regime de direitos humanos se tornou a estrutura fática e contrafactual do comércio internacional. A história da construção dos direitos humanos é antiga, mas sua versão moderna pode ser encontrada desde as Revoluções Atlânticas que eclodiram na Europa e na América do Norte e do Sul no final do século XVIII e início do século XIX (BRUNKHORST, 2014, p. 233). Especialmente quanto ao alcance dos direitos humanos, o movimento abolicionista foi essencial (MARTINEZ, 2014), embora uma mudança paradigmática em termos de propósito e extensão dos direitos humanos somente tenha ocorrido na segunda metade do século $X X$, como consequência do processo de descolonização (MOYN, 2010). ${ }^{21}$

Embora a história do regime global de direitos humanos seja marcada por continuidades e rupturas, o debate até o momento tem sido conduzido por historiadores do direito sem muita ênfase na perspectiva sociológica do direito acerca da mudança do status dos direitos humanos durante a terceira onda de globalização. Nas democracias institucionalmente estáveis e bem estabelecidas, as garantias constitucionais básicas são direitos reconhecidos relacionados à sua realização operacional no Estado de direito com a dupla função de assegurar a diferenciação funcional e autonomia individual (LUHMANN, 1965; VERSCHRAEGEN, 2002, 2006). Os direitos humanos possuem dupla função, podendo ambas ser descritas em termos constitucionais: a primeira, a de assegurar, a partir de sua legitimação, a estabilização do regime de transferências em escala global. Esse seria o caso, por exemplo, as diretrizes internas de direitos humanos nas empresas (JAPP, 2015), bem como os regimes mais amplos que constituem as estratégias de responsabilidade social corporativa (BUHMANN, 2015). Tais estratégias têm por finalidade a homogeneização da comunicação através das fronteiras, viabilizando, portanto, a internalização multicontextual dos direitos humanos, isto é, a compatibilização simultânea dos componentes sociais

\footnotetext{
${ }^{20}$ Para uma compreensão clássica sobre o tema, consultar: Koskenniemi (2001).

${ }^{21}$ Para uma terceira via entre Jenny Martinez e Samuel Moyn, conferir: Alston (2013), Walker (2015, p. 73) e Jensen (2016).
} 
condensados no interior dos múltiplos ambientes sociais nos diferentes estágios das cadeias produtivas. Os dez princípios do Pacto Global da ONU sobre direitos humanos nas empresas e outros regimes semelhantes contribuem com um reforço de segunda ordem à estabilização da plataforma jurídica e operacional-administrativa dos processos econômicos mundiais em curso, recebendo, assim, um caráter de princípios constitucionais que indicam a hierarquia de normas referentes a estes processos.

Em segundo, os regimes contemporâneos de direitos humanos, em oposição às formas coloniais de justificação e normalização, não estão firmados em uma diferenciação assimétrica, como ocorria com a noção colonial de cristão e de não cristão, por exemplo. Faticamente, contudo, os regimes contemporâneos tendem a se sustentar em assimetrias intrínsecas, imanentes, em termos de recursos e de articulação entre valores e finalidade (KJAER, 2010). Isso confere ao regime global de direitos humanos uma função programática em um contexto societário mais amplo, mas também em um sentido jurídico mais estrito quanto à sua realização. Em termos de sociedade mundial, cabe compreender o propósito dos direitos humanos como o de realizar a diferenciação funcional e a autonomia individual nas partes do mundo caracterizadas pela "miscigenação comunicativa e crioulização". Juridicamente, o que confere uma posição estratégica de valor constitucional em um sistema jurídico é a função de uma norma enquanto a plataforma que permite a transferência das transferências, ou, concretamente, a função do regime global de direitos humanos é a de facilitar as transferências das normas jurídicas voltadas a facilitar as transferências societárias mais abrangentes, como, por exemplo, dos componentes sociais condensados em termos de economia ou religião. Em outras palavras, a orientação contrafactual do regime global de direitos humanos é a de conduzir as normas jurídicas que surgiram no Ocidente para uma aplicação em escala global, isto é, a de universalizar o sistema jurídico do direito ocidental (SUPIOT, 2003). Decorre, por conseguinte, a afirmação de que este regime global estaria constitucionalizando o próprio sistema do direito global.

\section{Conclusão}

No escopo das teorias sistêmicas, desenvolveu-se uma teoria sofisticada sobre o constitucionalismo societário global. Esta nova abordagem oferece alguns insights para a possibilidade de constitucionalização dos processos globais, além de se configurar uma perspectiva alternativa, posicionando-se de forma ortogonal às teorias sistêmicas, mas com 
o fundamento em uma inflexão epistemológica que transitou do foco na diferenciação para o foco em conectividade. O principal argumento desenvolvido é o de que as estruturas jurídico-normativas globais caracterizam-se principalmente pela presença de normas de conectividade, em contraposição às normas de coerência e de possibilidade. As normas de conectividade destinam-se a facilitar a transferência de componentes sociais condensados - por exemplo, de natureza econômica ou religiosa - de um contexto juridicamente estruturado para outro. Observe-se que as normas de conectividade pertencem ao tipo de normas predominante no direito colonial e ainda são majoritárias no regime contemporâneo de governança global. No entanto, embora as normas de conectividade busquem reproduzir de forma idêntica as funções de transferência, elas se assentam em parâmetros normativos fundamentalmente diferentes. Devem, portanto, ser compreendidas como equivalentes funcionais, mas não equivalentes normativos. Porque, por um lado, o colonialismo assentava-se em distinções fortemente assimétricas, como ocorria pelo binômio cristãonão cristão; por outro, a governança global contemporânea assenta-se em distinções assimétricas subjacentes ao regime global de direitos humanos que, justamente, oferece um reforço de segunda ordem à função de constitucionalização por meio do papel intrínseco de normas que facilitam a transferência no conjunto do direito como um todo.

\section{Referências}

ALSTON, Philip. Does the Past Matter? On the Origins of Human Rights An Analysis of Competing Histories of the Origins of International Human Rights Law. Harvard Law Rev., v. 126, n. 7, p. 2043-2081, 2013.

AMSTUTZ, Marc. Métissage - Zur Rechtsform in der Weltgesellschaft. In: FISCHERLESCANO, Andreas; RÖDL, Florian; SCHMID, Christoph (Ed.). Europäische Gesellschaftsverfassung - Konstitutionalisierung sozialer Demokratie in Europa. BadenBaden: Nomos, 2009. p. 333-351.

AMSTUTZ, Marc; KARAVAS, Vagios. Weltrecht: Ein Derridasches Monster. In: CALLIESS, Graf-Peter et al. (Ed.). Soziologische Jurisprudenz: Festschrift für Gunther Teubner zum 65. Geburtstag. Berlin: Walter de Gruyter, 2009. p. 646-672.

AVBELJ, Matej. The Concept and Conceptions of Transnational and Global Law. WZB Discussion, Paper SP IV 2016-801, Feb. 23, 2016. Available at: https://ssrn.com/abstract=2753776. Accessed on: Mar. 20, 2020. 
BACKER, Larry Catá. Economic Globalization and the Rise of Efficient Systems of Global Private Lawmaking: Wal-Mart as Global Legislator. University of Connecticut Law Review, v. 39, n. 4, p. 1-46, 2007. Available at: https://ssrn.com/abstract=953216. Accessed on: Mar. $18,2020$.

BAR, Christian von et al. (Ed.). Principles, Definitions and Model Rules of European Private Law: Draft Common Frame of Reference (DCFR). Munich: Sellier European Law Publishers, 2009. v. 2.

BLAKE, Judith; DAVIS, Kingsley. Norms, Values and Sanctions. In: FARIS, Robert E. L. (Ed.). Handbook of Modern Sociology. Chicago IL: Rand McNally, 1964. p. 456-484.

BRUNKHORST, Hauke. Constitutionalism and Democracy in the World Society. In: DOBNER, Petra; LOUGHLIN, Martin (Ed.). The Twilight of Constitutionalism? Cambridge: Cambridge University Press, 2010. p. 179-198.

BRUNKHORST, Hauke. Critical Theory of Legal Revolutions: Evolutionary Perspectives. London: Continuum, 2014.

BUHMANN, Karin. Business and Human Rights: Understanding the UN Guiding Principles from the Perspective of Transnational Business Governance Interactions. Transnational Legal Theory, v. 6, n. 2, p. 399-434, 2015.

FASSBENDER, Bardo. 'We the Peoples of the United Nations': Constituent Power and Constitutional Form in International Law. In: LOUGHLIN, Martin; WALKER, Neil ( Ed.). The Paradox of Constitutionalism: Constituent Power and Constitutional Form. Oxford: Oxford University Press, 2008. p. 269-290.

FISCHER-LESCANO, Andreas; TEUBNER, Gunther. Regime-Kollisionen: Zur Fragmentierung des globalen Rechts. Frankfurt am Main: Suhrkamp, 2006.

FOSSUM, John Erik; MENÉNDEZ, Agustín José. The Constitution's Gift: A Constitutional Theory for a Democratic European Union. Lanham MD: Rowman \& Littlefield, 2011.

GADAMER, Hans-Georg. Hermeneutik I: Wahrheit und Methode: Grundzüge einer philosophischen Hermeneutik. Tübingen: J.C.B. Mohr, 1986/1990. Gesammelte Werke, v. 1, p. 310.

GRANDMAISON, Olivier Le Cour. L'exception et la règle: sur le droit colonial français. Diogène, v. 212, n. 4, p. 42-64, 2005. https://doi.org/10.3917/dio.212.0042

HALLIDAY, Terence C.; SHAFFER, Gregory (Ed.). Transnational Legal Orders. New York: Cambridge University Press, 2015.

HANNA, Mark. Between Law and Transnational Social Movement Organizations: Stabilizing Expectations of Global Public Goods. Journal of Law and Society, v. 44, n. 3, p. 345-373, 2017.

HYDÉN, Håkan. Normvetenskap. Lund: Lund University Press, 2002. 
JAPP, Klaus Peter. Zur Funktion der Menschenrechte in der Weltgesellschaft - Niklas Luhmanns 'Grundrechte als Institution' Revisited. In: HEINTZ, Bettina; LEISERING, Britta (Ed.). Menschenrechte in der Weltgesellschaft, Deutungswandel und Wirkungsweise eines globalen Leitwerts. Frankfurt am Main: Campus, 2015. p. 65-97.

JENSEN, Steven L. B. The Making of International Human Rights: The 1960s, Decolonization, and the Reconstruction of Global Values. Cambridge: Cambridge University Press, 2016.

JESSUP, Philip C. Transnational Law. New Haven CT: Yale University Press, 1956.

JOERGES, Christian; KJAER, Poul F.; RALLI, Tommi. A New Type of Conflicts Law as Constitutional Form in the Postnational Constellation. Transnational Legal Theory, v. 2, n. 2, p. 153-165, 2011.

KJAER, Poul F. Systems in Context: On the Outcome of the Habermas/Luhmann-debate. Ancilla luris, p. 66-77, 2006.

KJAER, Poul F. The Metamorphosis of the Functional Synthesis: A Continental European Perspective on Governance, Law and the Political in the Transnational Space. Wisconsin Law Review, v. 2010, n. 2, p. 489-533, 2010. Available at: https://ssrn.com/abstract=1668423. Accessed on: Apr. 22, 2020.

KJAER, P. F. Law of the Worlds: Towards an Inter-Systemic Theory. In: KELLER, Stefan; WIPRÄCHTIGER, Stefan (Ed.). Recht zwischen Dogmatik und Theorie: Marc Amstutz zum 50. Baden-Baden: Nomos, 2012. p. 159-175.

KJAER, Poul F. Constitutionalism in the Global Realm: A Sociological Approach. Abingdon: Routledge, 2014.

KJAER, Poul F. Constitutionalizing Connectivity: The Constitutional Grid of World Society. Journal of Law and Society, v. 45, n. s1, p. S114-S134, July 2018a.

KJAER, Poul F. Facilitating transfers: regulatory governance frameworks as 'rites of passage'. Contemporary Politics, v. 24, n. 5 - Regulatory Governance: rules, resistance and responsibility, p. 507-523, 2018b.

KLABBERS, Jan. Of Round Pegs and Square Holes: International Law and the Private Sector. In: JURCYS, Paulius; KJAER, Poul. F.; YATSUNAMI, Ren (Ed.). Regulatory Hybridization in the Transnational Sphere. Leiden: Martinus Nijhoff, 2013. p. 29-48.

KORSGAARD, Christine. The Sources of Normativity. New York: Cambridge University Press, 1996.

KOSKENNIEMI, Martti. The Gentle Civilizer of Nations: The Rise and Fall of International Law 1870-1960. Cambridge: Cambridge University Press, 2001.

KOSKENNIEMI, Martti. Legal Fragmentations - An Essay on Fluidity and Form. In: CALLIESS, Graf-Peter et al. (Ed.). Soziologische Jurisprudenz: Festschrift für Gunther Teubner zum 65. Geburtstag. Berlin: Walter de Gruyter, 2009. p. 795-810. 
KOSKENNIEMI, Martii. Empire and International Law: The Real Spanish Contribution. University of Toronto Law Journal, v. 61, n. 1, p. 1-36, 2011.

KOSKENNIEMI, Martti. Colonial Laws: Sources, Strategies and Lessons? Journal of the History of International Law, v. 18, n. 2-3, p. 248-277, 2016. https://doi.org/10.1163/15718050-12340059

KRISCH, Nico. Beyond Constitutionalism: The Pluralist Structure of Postnational Law. Oxford: Oxford University Press, 2010.

LANDO, Ole. A Global Commercial Code. Recht der Internationalen Wirtschaft, v. 3, p. 161162, 2004.

LARKIN, Brian. The Politics and Poetics of Infrastructure. Annual Review of Anthropology, v. 42, n. 1, p. 327-342, 2013. https://doi.org/10.1146/annurev-anthro-092412-155522

LE GOLF, Pierrick. Global Law: A Legal Phenomenon Emerging from the Process of Globalization. Indiana Journal of Global Legal Studies, v. 14, n. 1, p. 119-145, 2007. Available at: https://www.repository.law.indiana.edu/ijgls/vol14/iss1/7. Accessed on: 18 mar. 2020.

LUHMANN, Niklas. Grundrechte als Institution: Ein Beitrag zur politischen Soziologie. Berlin: Duncker \& Humblot, 1965.

LUHMANN, Niklas. Zweckbegriff und Systemrationalität: Über die Funktion von Zwecken in sozialen Systemen (1968). Frankfurt am Main: Suhrkamp, 1973.

LUHMANN, Niklas. Rechtssystem und Rechtsdogmatik. Stuttgart: W. Kohlhammer, 1974.

LUHMANN, Niklas. Verfassung als evolutionäre Errungeschaft. Rechtshistoriches Journal, v. 9 , p. $176-220,1990$.

LUHMANN, Niklas. Kausalität im Süden. Soziale Systeme, v. 1, n. 1, p. 7-28, 1995.

LUHMANN, Niklas. Quod Omnes Tangit: Remarks on Jurgen Habermas's Legal Theory. Cardozo Law Review, v. 17, p. 883-899, 1996.

LUHMANN, Niklas. Die Gesellschaft der Gesellschaft. Frankfurt a/Main: Suhrkamp, 1997.

LUHMANN, Niklas. Rechtssoziologie Auflage: 4 (1972). Wiesbaden: VS Verlag für Sozialwissenschaften, 2008.

LUHMANN, Niklas. Die Weltgesellschaft (1971). 6. ed. In: Soziologische Aufklärung 2: Aufsätze zur Theorie der Gesellschaft. Wiesbaden: VS Verlag für Sozialwissenschaften, 2009. p. 51-71.

MADSEN, Mikael Rask; THORNHILL, Christopher (Ed.) Introduction: Law and the Formation of Modern Europe - Perspectives from the Historical Sociology of Law. In: . Law and the Formation of Modern Europe: Perspectives from the Sociology of Law. Cambridge: Cambridge University Press, 2014. p. 1-26. 
MANNING, Patrick. The Slave Trade: The Formal Demography of a Global System. In: INIKORI, Joseph E.; ENGERMAN, Stanley L. (Ed.). The Atlantic Slave Trade: Effects on Economies, Societies and Peoples in Africa, the Americas, and Europe. Durham NC: Duke University Press, 1992. p. 117-144.

MBEMBE, Achille. Qu'est-ce que la pensée postcoloniale? Esprit, déc. 2006. Disponible en: https://esprit.presse.fr/article/achille-mbembe/qu-est-ce-que-la-pensee-postcolonialeentretien-13807. Consulté le: 22 fév. 2020.

MARTINEZ, Jenny. The Slave Trade and the Origins of International Human Rights. Oxford: Oxford University Press, 2014.

MEYER, John W. et al. World Society and the Nation-State. American Journal of Sociology, v. 103, n. 1, p. 144-181, 1997.

MÖLLERS, Christoph. Die Moglichkeit der Normen: Über eine Praxis jenseits von Moralität und Kausalität. Berlin: Suhrkamp, 2015.

MOYN, Samuel. The Last Utopia: Human Rights in History. Cambridge MA: Harvard University Press, 2010.

NEVES, Marcelo. Verfassung und Positivität des Rechts in der peripheren Moderne. Berlin: Duncker und Humblot, 1992.

OSTERHAMMEL, Jurgen. The Transformation of the World: A Global History of the Nineteenth Century. Traduzido por Patrick Camiller. Princeton: Princeton University Press, 2014.

PALOMBELLA, Gianluigi. Global Law and the Law on the Globe: Layers, Legalities and the Rule of Law Principle. Italian Journal of Public Law, n. 4, p. 53-92, 2012.

PARSONS, Talcott. The Structure of Social Action: A Study in Social Theory with Special Reference to a Group of Recent European Writers (1937). New York: Free Press, 1968.

SANTOS, Boaventura de Sousa. Toward a New Legal Common Sense: Law, Globalization and Emancipation. 2nd ed. London: Butterworths, 2002.

SASSEN, Saskia. The Global City: New York, London, Tokyo. Princeton: Princeton University Press: 2001.

SASSEN, Saskia. Territory, Authority, Rights: From Medieval to Global Assemblages. Princeton/Oxford: Princeton University Press, 2006.

SCHMITT, Carl. Der Nomos der Erde: Im Völkerrecht des Jus Publicum Europaeum. Köln: Greven, 1950.

SIMMEL, Georg. Wie ist Gesellschaft moglich. In: Untersuchungen über die Formen der Vergesellschaftung. Berlin: Duncker \& Humblot, 1908. p. 22-30.

STICHWEH, Rudolf. Die Weltgesellschaft: Soziologische Analysen. Frankfurt: Suhrkamp, 2000. 
STICHWEH, Rudolf. Transfer in Sozialsystemen: Theoretische Überlegungen. In: DUSS, Vanessa et al. (Ed). Rechts-transfer in der Geschichte. Munich: Martin Meidenbauer, 2006. p. 1-13.

STICHWEH, Rudolf. Das Konzept der Weltgesellschaft: Genese und Strukturbildung eines globalen Gesellschaftssystems'. Rechtstheorie, v. 39, n. 2-3, p. 329-355, 2008.

SUPIOT, Alain. The Labyrinth of Human Rights: Credo or Common Resource? New Left Review, n. 21, p. 118-136, May-June 2003.

SUPIOT, Alain. The Territorial Inscription of Law. In: CALLIESS, Graf-Peter et al. (Ed.). Soziologische Jurisprudenz: Festschrift für Gunther Teubner zum 65. Geburtstag am 30 April 2009. Berlim: Walter de Gruyter, 2009, p. 375-393.

SUPPLY Chain. Wikipedia, Feb 22, 2003. Available at: https://en.wikipedia.org/wiki/Supply_chain. Accessed on: April 20, 2020.

TEUBNER, Gunther. Constitutional Fragments: Societal Constitutionalism and Globalization. Oxford: Oxford University Press, 2012.

THORNHILL, Christopher. A Sociology of Transnational Constitutions: The Social Foundations of the Post-National Legal Structure. Cambridge: Cambridge University Press, 2016.

TUORI, Kaarlo Heikki; TUORI, Klaus. The Eurozone Crisis: A Constitutional Analysis. Cambridge: Cambridge University Press, 2014.

UNITED NATIONS. Charter of the United Nations. Jun. 26, 1945. Available at: https://www.un.org/en/charter-united-nations/. Accessed on: Mar. 22, 2020.

UNITED NATIONS. Global Compact. The Ten Principles of the UN Global Compact. Page modified on May 17, 2020. Available at: https://www.unglobalcompact.org/what-isgc/mission/principles. Accessed on: May 17, 2020.

VERSCHRAEGEN, Gert. Human Rights and Modern Society: A Sociological Analysis from the Perspective of Systems Theory. Journal of Law and Society, v. 29, n. 2, p. 258-281, 2002.

VERSCHRAEGEN, Gert. Systems Theory and the Paradox of Human Rights. In: KING, Michael; THORNHILL, Christopher (Ed.). Luhmann on Law and Politics: Critical Appraisals and Applications. Oxford-Portland OR: Hart Publishing, 2006. p. 101-125.

WALKER, Neil. Intimations of Global Law. Cambridge: Cambridge University Press. 2015.

XIFARAS, Mikhail. The Global Turn in Legal Theory. The Canadian J. of Law \& Jurisprudence, v. 29, n. 1, p. 215-219, fev. 2016. 